\title{
LA RELIGIÓN-GÉNERO COMO MEDIACIÓN DE SOCIALIDAD Y VISIBILIDAD \\ UN ESTUDIO DE CASOS DE LAS MUJERES \\ PERTENECIENTES A COMUNIDADES RELIGIOSAS \\ MINORITARIAS EN ARAGÓN
}

\section{RELIGION-GENDER AS MEDIATION OF SOCIALITY AND VISIBILITY}

A CASE STUDY OF WOMEN BELONGING TO RELIGIOUS MINORITIES COMMUNITIES IN ARAGON

AleXIa SAnz Hernández ${ }^{*}$

Resumen: El artículo propone un análisis de la comprensión que tienen las mujeres integrantes de comunidades religiosas minoritarias presentes en contextos urbanos aragoneses (musulmana, evangélica y ortodoxa) acerca de la mediación de dicha pertenencia $y$ de su condición femenina, en sus dinámicas de visibilidad y de socialidad. Para ello, desde una perspectiva etnometodológica, se ha realizado un análisis del discurso obtenido a partir de entrevistas en profundidad a mujeres pertenecientes a estas denominaciones religiosas minoritarias. Estas mujeres comparten una comprensión de su visibilidad marcada por una múltiple otredad: la que se deriva de su religión, la de foraneidad que se asocia a la misma y la femenina. Al mismo tiempo, existe una dualidad emocional y funcional de la comunidad religiosa como mediación de las dinámicas de socialidad. Visibilidad y socialidad se articulan en la mediación que implica la condición femenina y la pertenencia religiosa de estas mujeres.

* Universidad de Zaragoza. 
Palabras clave: mujer, comunidades religiosas minoritarias, visibilidad, socialidad, inmigración.

Abstract: The text aims to analyse how women from religious minority communities (Muslim, Evangelic and Orthodox ones) living in urban Aragonian contexts see this religious belonging as well as their woman condition, mediate their dynamics of sociability and social visibility. From an ethnomethodological perspective, we conducted discourse analysis to the discourse obtained through in-deep interviews to women who belong to these religious minorities. These women share a common understanding on a visibility signed by a multiple otherness: this derived from their religion, the foreignness associated to it, and their woman condition. At the same time, there is a dual -both emotional and functional - nature to the religious communities as mediation of dynamics of sociability for these women. Visibility and sociability are articulated, to this way, on the mediation derived from the women condition and the religious belonging.

Keywords: woman, religious minorities' communities, visibility, sociability, immigration.

\section{INTRODUCCIÓN ${ }^{1}$}

Los estudios de sociología de la religión tienen como postulado fundador la incompatibilidad entre religión y racionalidad moderna, asociada a la secularización y el desencantamiento. En correspondencia con la oposición religiosidad/secularización, los análisis sobre la religión han insistido en relacionar la autonomía progresiva de las distintas esferas de la vida cotidiana (política, economía, ciencia, comunicación, familia, afectos, etcétera) con una creciente marginalización y declinación de la religión organizada o institucional

1 La mayor parte del trabajo de campo que sustenta este artículo fue realizado en el marco de varios proyectos financiados por la Fundación Pluralismo y Convivencia para el estudio de la situación de las confesiones minoritarias en Aragón (2007-2009). Dicha Fundación ha impulsado trabajos interesantes en diferentes comunidades autónomas españolas, que han dado lugar a una colección ineludible y muy recomendable sobre las minorías religiosas en España. 
con respecto a aquellas mismas esferas. Como apunta Pace (1995: 105-106), incluso en propuestas teóricas más recientes, la religión se presenta con una gradual pérdida de visibilidad social y de su función de integración social, quedando recluida a la condición de hecho individual, crecientemente privatizado, con un encargo, sobre todo, de recurso interpretativo.

Si incorporamos la variable de género al análisis, cabe decir que en una sociología de la religión tradicionalmente marcada por el etnocentrismo y el androcentrismo, el tema del análisis de las interrelaciones entre la religiosidad y la condición femenina se presenta particularmente complejo y necesario. El sexismo, explícito en visiones marcadamente androcéntricas de Dios, la humanidad y el Cosmos, es una cuestión central en la mayoría de las tradiciones religiosas (Tarducci, 1992). En los discursos de las grandes religiones mundiales sería difícil hallar una perspectiva de igualdad de oportunidades religiosas entre hombres y mujeres; más bien debe hablarse de legitimación más o menos explícita del dominio de los primeros sobre las segundas (Pace, 1995).

Esta cuestión es mucho más significativa en el escenario español, caracterizado por una secularización y una multiplicación de las religiosidades, tardías, como consecuencia del reforzamiento del catolicismo y la exclusión y el olvido que supuso el régimen franquista para las minorías religiosas ${ }^{2}$ (Rozenberg, 1996). En tal contexto, los estudios sobre mujer y religión se presentan, especialmente en el caso de las minorías religiosas, como una indagación en una doble condición minoritaria o subordinada: la religiosa (minoría real en este caso) y la de género (minoría simbólica en muchas ocasiones). Así, el acercamiento a la mediación de la dimensión religiosa en las prácticas de visibilidad y socialidad ${ }^{3}$ de las mujeres pertenecientes a minorías religiosas, que se presenta en este artículo, es pertinente en un contexto de secularización creciente y de ampliación y consolidación de las políticas públicas de igualdad.

2 En el contexto de la sociedad española, se consideran minorías religiosas aquellas denominaciones distintas de la Iglesia Católica con una implantación histórica en España, pero que han permanecido ocultadas o silenciadas, bajo la idea hegemónica del catolicismo como fundamento de la sociedad. En general, se suelen incluir entre las mismas a las religiones musulmana, judía y protestante, con las cuales el Estado firmó, el 21 de febrero de 1990, unos Acuerdos de Cooperación.

3 Asumiendo la noción maffesoliana. 
Tal análisis se localiza en la tensión, propia de lo religioso, entre el movimiento de privatización por un lado y la condición comunitaria por otro; esto es: de la tensión entre el sujeto-lo individual y lo colectivo-comunitario que atraviesa a $-\mathrm{y}$ es atravesado por- la dimensión religiosa.

Finalmente, cabe observar que en sociedades históricamente mono-religiosas, los procesos de configuración de comunidades religiosas minoritarias aparecen ligados a dos fuentes, claves en nuestro propósito analítico: la conversión y la migración.

\section{MUJER Y RELIGIÓN: ANTECEDENTES Y LÍNEAS TEÓRICAS GENERALES}

Hemos introducido tres pares de dualidades, cuyo entrecruzamiento dibuja el escenario analítico a explorar: lo individual y lo comunitario-colectivo; la visibilidad y la socialidad; y, finalmente, la conversión y la inmigración. El eje que atraviesa esa tríada de dualidades es la dimensión del género, al considerar que las redefiniciones de las identidades sexo-género se hallan inherentemente vinculadas con el modo en que las mujeres viven su religión e interactúan en sus comunidades minoritarias religiosas y con otras comunidades religiosas, con las organizaciones civiles de la sociedad y, finalmente con ésta, en sentido general.

Mientras los estudios sobre mujer e inmigración han sido más habituales - en especial a partir de los 90, con la aparición de flujos migratorios en algunos casos casi exclusivamente femeninos-, la variable de la religión ha sido menos frecuente en los estudios de género, aunque también desde inicios de los 80 comenzó a considerarse por algunos estudios feministas. A partir de entonces, ciertos análisis empiezan a destacar la presencia —en los países católicosde las mujeres en la Iglesia, al punto que ésta podría considerarse un «espacio de mujeres» - llegándose a ver incluso con una naturaleza en cierta forma subversiva- pues a pesar de estar dominada por los hombres, con frecuencia es un lugar de «encuentro, de devoción y de conversación entre mujeres» (Bates et al, 1994).

En las denominaciones protestantes, como precisa Tarducci (1992), son conocidas sus correlaciones con el feminismo. El protestantismo se distancia así de la tendencia general sexista en las 
tradiciones religiosas. Numerosos autores otorgan a la ideología social del protestantismo liberal una importancia equiparable a la filosofía de la ilustración para el desarrollo e inspiración del feminismo sufragista del siglo xix. No es casual que los países protestantes hayan sido el escenario tanto del surgimiento del movimiento feminista, como de producción de los estudios sobre género y religión. En las agrupaciones evangélicas, «precisamente por su organización más laxa, y porque sus prácticas dependen más de la emotividad y la espontaneidad que de la formación teológica, las mujeres han tenido históricamente un papel más relevante» (Tarducci, 1992: 108-109).

Pero, más allá de esta singularidad del protestantismo, en general existe un conflicto entre la autonomía religiosa o cultural y la igualdad de género. Este sería, por ejemplo, uno de los puntos críticos en el sistema de relaciones internacionales, pues en nombre de la libertad religiosa o cultural se llega a reclamar inmunidad frente a las normativas internacionalmente establecidas respecto a la igualdad de género en el marco de la doctrina universal de los derechos humanos (Raday, 2004: 663). Dicho conflicto, con variaciones entre las diferentes regiones y religiones, emerge en la mayoría al descansar «en normas y prácticas sociales formuladas o interpretadas en un contexto patriarcal, en una época en la cual los derechos humanos individuales, en general, y el derecho de la mujer a la igualdad, en particular, no habían devenido aún un imperativo global» (Ídem: 664).

Raday (Ídem: 695-710) analiza tres perspectivas teóricas para defender la diferencia cultural o religiosa en ese conflicto entre cultura/religión e igualdad de género. En primer lugar, el enfoque multiculturalista, según el cual la preservación de la autonomía de la comunidad es un valor suficientemente importante que prevalece sobre las demandas de igualdad. El segundo, denominado «enfoque del consenso", propone que "si los valores culturales o religiosos cuentan con la sanción del consenso político en un sistema democrático, entonces ello es suficiente para legitimar su hegemonía». Finalmente, el enfoque del "consentir o abandonar/renunciar» (consent or waiver), según el cual si existe consentimiento individual de los valores religiosos o culturales, estos se deben respetar, aunque sea discutible la validez del consentimiento femenino a la desigualdad en un entorno marcadamente patriarcal.

Cada una de estas perspectivas estaría asociada a una postura en relación con el eje individualidad-comunidad. En los enfoques 
multiculturalista y del consenso habría un predominio de lo comunitario frente a lo individual. En el caso de la perspectiva del consent or waiver, la individualidad femenina tendría un mayor peso, aunque en un contexto patriarcal resulte cuestionable la verdadera calidad de esa individualidad.

A las complicaciones inherentes a la tensión religión/género, se agregarían, en el caso del análisis en escenarios donde estas comunidades religiosas son minoritarias, las que se derivan de dicha circunstancia. Esta última suma nuevas complejidades en la comprensión de la mediación que la pertenencia a las mismas supone para las dinámicas de visibilidad y socialidad de las mujeres miembros, y por ende de la tensión de tal membresía con la dimensión del género. Sobre todo en un contexto donde existe una marcada conflictividad entre las políticas públicas de igualdad y las posturas que, en relación con ello, asumen estas religiones minoritarias.

En España, los estudios sobre mujer y religión -y, en especial, minorías religiosas-, se han incrementado durante la pasada década, como respuesta - y confirmación - al incremento de los flujos migratorios hacia el país, al proceso de feminización de parte de esa inmigración, y la modificación del panorama religioso nacional tras la institucionalización de las minorías religiosas $-\mathrm{y}$ el correlativo incremento de sus vínculos con las instituciones de la administración y la ampliación de su actuación en esferas como la acción social-.

Algunos estudios (Dietz, 2004; Rodríguez Martínez, 2005; Tarré Chamorro, 2008, Sanz Hernández, 2009) han analizado, específicamente, el nexo minorias religiosas-género o género-migración; y lo han hecho sobretodo desde la perspectiva emic, ofreciendo, por ejemplo, un acercamiento a la compleja diversidad de autodefiniciones y discursos identitarios, manifiesta en el caso de las musulmanas, frente a una percepción externa que, por lo general, se presenta homogeneizada, y que las ve como víctimas reales o potenciales de su pertenencia religiosa. En tal sentido, uno de los aspectos que se destaca es precisamente la marcada influencia de la socialidad en la identidad religiosa de las féminas que pertenecen a esta comunidad minoritaria, en una dinámica en la cual la instrucción religiosa no es una tarea distintiva en el proceso de socialidad y el hogar se considera como lugar fundamental, frente a otros agentes sociales menores —en términos religiosos- como la mezquita y la escuela (Dietz, 2004). 
En el caso de la comunidad musulmana, diferentes estudios coinciden en la fragmentación de la escasa vida comunitaria y asociativa (Dietz, 2004) y en su importante falta de organización desde el punto de vista de la intervención social, para la cual presentan una dependencia de otras instituciones, a pesar de estar entre las comunidades minoritarias religiosas más antiguas y numerosas (Hernando de Larramendi y García Ortiz, 2009). Al mismo tiempo, en algunos casos se destaca la diferencia en las dinámicas de socialidad y asociativas entre inmigrantes y conversos —más sólidas en el caso de estos últimos-, así como la complementación y reforzamiento mutuo de las percepciones técnicas de la alteridad religiosa y cultural y las tendencias generalizadas de exclusión y victimización de las mujeres musulmanas (Dietz, 2004).

La feminización de la inmigración, por su parte, ha sido objeto de análisis comparativos de las identificaciones de sexo-género entre mujeres de diferentes nacionalidades de origen (Rodríguez Martínez, 2005). En este caso, la mediación relacional entre lo individual y lo colectivo en la configuración del tejido de - siguiendo la distinción propuesta por Sotolongo y Delgado (2006)— vínculos y relaciones sociales está presente tanto en el seno de los grupos de mujeres como entre ellos. En particular, en el nivel intragrupal, el sexo-género se considera en tanto que variable relacional, mientras en el intergrupal se asocia a un recurso étnico. Significativamente, el eje visibilización-socialidad se presenta como cuestión central en el análisis, pues una de las principales dimensiones comparativas entre las mujeres de distintas nacionalidades de origen es la calidad de sus redes sociales, o la tendencia a la individualización de problemas colectivos, como es la violencia de género.

De igual forma, también la conversión religiosa ha sido tema de investigación (Tarré Chamorro, 2008), en tanto que fenómeno creciente en los últimos años en la sociedad española, de la mano del aumento de los flujos migratorios hacia la Península Ibérica. También en estos análisis específicos, se insiste en la feminización de algunas de estas comunidades religiosas minoritarias, como es el caso del Islam. Así mismo, en el examen del proceso de conversión, se destaca otra vez el carácter dual —individual y social individual— del mismo.

La conversión implica una transformación multidimensional, desde lo cognitivo e identitario individual, hasta lo identitario social, las actitudes y los comportamientos en los diversos escenarios 
sociales. Mientras en las conversiones de tipo intelectual —predominantes hasta los 80 - prevalecerá lo individual, en el período que se inicia a partir de mediados de los años 90, el predominio de conversiones de carácter místico, afectuoso o afectivo, experimental, revivalístico u obligatorio, estará asociado a conversiones femeninas ligadas al contexto migratorio, por relaciones de amistad, socialidad y/o matrimonio con inmigrantes musulmanes.

Tales estudios precedentes confirman, así, la pertinencia de analizar las mediaciones entre género y religión en las mujeres de diferentes minorías religiosas, que contemple como ejes centrales la comprensión de cómo esa mediación atraviesa - y es atravesada por- los tres pares de dualidades mencionados anteriormente.

\section{ARAGÓN COMO CONTEXTO ANALÍTICO: MIGRACIONES, MUJER Y RELIGIONES}

Las comunidades religiosas minoritarias presentes en la sociedad española en general, y aragonesa en particular ${ }^{4}$, han presenciado un dinamismo inusitado en el siglo actual, fundamentalmente a partir de los dos procesos simultáneos y paralelos ya referidos: la incorporación de nuevas adeptas inmigrantes que pertenecían a estas minorías religiosas, y las conversiones desde el catolicismo, cada vez más frecuentes por otro lado. Nótese que la intensificación de los procesos migratorios y el revisionismo religioso inherentemente ligado a la transión democrática, están tras la aparición y el

4 Según cifras del Anuario Estadístico de Inmigración del OPI, a finales de 2009 la población inmigrante con permiso de residencia en España ascendía a casi 4,8 millones de personas, de las cuales un 46,5\% eran mujeres. La población inmigrante que eligió Aragón como lugar de residencia suponía solo un 3,5\% del total nacional, de la cual 73.267 eran mujeres (el 43\%). En Aragón, las nacionalidades presentes más numerosas son Rumanía (34,5\%), Marruecos (12\%), Ecuador $(8 \%)$, Colombia (5\%) y Portugal $(3,5 \%)$, sumando el resto de nacionalidades casi un $37 \%$. Al hacer el análisis atendiendo al sexo, las tendencias generales se ven matizadas en los siguientes extremos: la población femenina supera a la masculina en más de dos puntos porcentuales en el caso de la procedencia desde Rumanía (que aglutina un 35,6\% de las mujeres inmigrantes), Ecuador (9,2\%), y Colombia $(6,36 \%)$. La feminización es clara en el caso de la población iberoamericana (por ejemplo, el 60\% de los inmigrantes de la República Dominicana son mujeres). 
fortalecimiento de las comunidades religiosas minoritarias en nuestro contexto.

En Aragón, particularmente, existe una clara delimitación entre aquellas comunidades religiosas cuya permanencia en el territorio se prolonga en el tiempo - de manera que el núcleo central de su membresía es la autoctoneidad - y las comunidades religiosas organizadas en torno a una identidad étnico-cultural diferenciada, cuyo crecimiento está vinculado directamente con la afluencia de población extranjera (y en menor grado con la conversión de españolas de tradición familiar católica), esto es, a la foraneidad. Este eje autoctoneidad-foraneidad debe comprenderse en paralelo e instrínsecamente asociado a la evolución de los procesos migratorios en la comunidad autónoma.

El perfil inmigrante en Aragón ha vivido una transformación, desde los años 90, marcada en gran medida por una feminización del mismo, a partir de un perfil original de hombre-musulmán-inmigrante regular y coincidiendo con la llegada de mayor número de inmigrantes evangélicas de Latinoamérica (Colombia, Ecuador y República Dominicana), primero, y de ortodoxas de la Europa del Este (Rumanía y Bulgaria) y fieles de la comunidad musulmana (Marruecos y Argelia), por motivos económicos o como fruto de la reagrupación familiar más reciente, después ${ }^{5}$.

Como resultado, la mujer inmigrante ha adquirido peso y representación en el territorio aragonés, aportando nuevas tonalidades a la migración tradicionalmente masculina, y contribuyendo notablemente a la visibilización — desde la condición femenina- de las diferentes comunidades religiosas minoritarias. Como muestran los estudios anteriores en el ambito aragonés, éste ha sido un proceso complejo muy proclive a la reproducción en el ámbito religioso de las distinciones de género hegemónicas asociadas a lo público-político, marcadamente masculinizado, y lo público-afectivo y privadodoméstico, básicamente feminizado (Sanz Hernández, 2009).

En este escenario de diversidad ampliada de la inmigración, en buena medida como correlato de su feminización, es donde se materializó esta indagación. Dado el carácter especialmente sensible del

5 Estas tres áreas principales de procedencia migratoria femenina delimitan igualmente el mapa aproximativo de las religiones principales que como minorías religiosas se manifiestan en Aragón como lugar de acogida: la ortodoxa, la evangélica y la musulmana. 
tema a investigar, en particular en el caso de algunas denominaciones religiosas, se optó por la entrevista individual en profundidad como técnica principal de investigación, con un cuestionario abierto no estructurado, que posibilitase un contexto conversacional proclive a fomentar un mayor clima de confianza en las informantes.

La selección de la red de informantes - un total de 26 residentes en las tres capitales de provincia aragonesas- se había realizado tomando como primer criterio su nacionalidad, garantizando la representación tanto de las nacionalidades con mayor presencia en Aragón (Rumanía, Marruecos, Colombia), como de otras menos importantes cuantitativamente, pero significativamente convenientes (Argelia, Argentina, República Dominicana, o Siria). De igual forma, se había considerado la comunidad religiosa minoritaria de pertenencia, con el objetivo de tener testimonios de las tres más relevantes presentes en la Comunidad Autónoma (musulmana, evangélica y ortodoxa) y su distribución territorial por la región. Dada la sensibilidad del tema, no fue posible establecer una mayor segmentación según otros criterios (edad, nivel de estudios u ocupación), sino que, definidos los tres ya mencionados, la identificación y el contacto con las informantes se realizó a partir de las redes personales - formales e informales - de la investigadora y de la disposición de aquellas a ser entrevistadas.

Finalmente, desde una perspectiva etnometodológica, se procedió al análisis de los discursos obtenidos en las entrevistas posibilitando tanto el análisis comparativo entre los sentidos asociados, en cada caso, a la mediación de la pertenencia religiosa en una socialidad y visibilidad desde la condición femenina, como también las propias visibilidades que las mujeres de las diferentes comunidades tienen entre sí.

\section{MEDIACIÓN DE LO RELIGIOSO MINORITARIO EN LA VISIBILIDAD SOCIAL FEMENINA}

La mediación de la religiosidad en la visibilidad social femenina aflora en el discurso de las mujeres de las tres comunidades analizadas; no obstante, existen diferencias entre ellas.

Por sus particularidades en la vestimenta —el velo-, la dimensión de la visibilidad es especialmente subrayada por las mujeres 
musulmanas. Particularmente, las conversas reconocen cómo la marca identitaria social que supone la conversión llega a ser mayor que el cambio que implica realmente en la identidad individual. Así, aunque «el día de Aragón, yo me siento igual de identificada con él (...) la gente en un principio, (...) se piensa que has dejado tu patria (...). Sobre todo las abuelitas, [te dicen] “imadre mía que has renegado de España!" "

La cuestión del vestuario es subrayada en este caso. Las mujeres reconocen que «si yo fuera musulmana pero no llevara el pañuelo pues no pasaría nada porque yo rezo en mi casa, nadie sabe si yo ayuno o como (...). Mis hijos van al colegio (...), hacen actividades extraescolares igual que todos; entonces, no se notaría; es el hecho de las manifestaciones externas, de la vestimenta ${ }^{7}$. El uso del pañuelo - explícito en los estudios referenciados- se confirma como el aspecto más complejo y polémico en la comprensión de la visibilidad social en las féminas musulmanas.

Pero no solo se trata de la imagen física, sino también de la representación social (Moscovici y Hewstone, 1986) que, a su juicio, tiene el Islam. Así, consideran que - al contrario de otras denominaciones religiosas minoritarias - el hecho de que «el Islam tiene muchas connotaciones malas en la sociedad (...) [y] no tiene una visión a través de los medios muy buena ${ }^{8}$, resulta una cuestión que incide marcadamente en esa mediación que tiene el hecho de ser - $\mathrm{O}$ haberse convertido en- musulmana, para su visibilidad social como mujer. Este énfasis en lo mediático es coherente con la especial dimensión comunicativa que se reconoce en las representaciones sociales (Moscovici y Hewstone, 1986; Jodelet, 1986).

Sobre todo en las musulmanas conversas, resulta significativa esa tensión entre la autocomprensión del cambio en la identidad individual — que ciertamente se reconoce, pero que no se llega a considerar cultural, en el sentido de ruptura total con lo español- y la representación social que se tiene de ese cambio; esto es, la identidad social que se asocia a estas mujeres. Aquí es central

6 Al referirnos a las informantes, se incorporan solo los datos necesarios para contextualizar adecuadamente las manifestaciones realizadas. En este caso, estamos ante una mujer de nacionalidad española, musulmana conversa y residente en Zaragoza.

7 Ídem.

8 Española, musulmana conversa, Huesca. 
la vinculación que se establece, en el imaginario dominante, entre una determinada religión - la católica- y la identidad nacional. La conversa rompe, ante los ojos de la sociedad dominante, con su pertenencia a esa comunidad imaginada (Anderson, 1993), y ello marca su nueva visibilidad social pero también su propia visión individual sobre esa visibilidad social, atravesada por una percepción de condena o rechazo por parte de la socialidad dominante.

Pero a pesar de su peso en la visibilidad social de este colectivo - como consecuencia de esa ruptura que representan-, las conversas son una minoría en la minoría. La mayoría de las mujeres musulmanas residentes en Aragón son inmigrantes. En este caso, también estas coinciden en que la representación social dominante de la religión musulmana marca la visión sobre las mujeres de esta comunidad religiosa, y por ello «la mujer musulmana sí que sufre un poco", pues "se piensa que las mujeres que llevan el velo son ignorantes, son sumisas, no tienen estudios, que no es libre, que siempre va detrás del hombre».

Esta imagen se habría ido transformando pues «cuando hemos empezado a integrarnos, en todos los sitios públicos, la gente se entera que no, que hay algunas que sí tienen estudios, y otras no» ${ }^{9}, \mathrm{y}$ además, la imagen "ha cambiado, un poco, con las asociaciones de mujeres musulmanas ${ }^{10}$. Se reconoce que la idea de la mujer musulmana "sí que ha cambiado un poco aunque no para todos» ${ }^{11}$, y en tal sentido se subraya nuevamente el papel de los medios de comunicación en la construcción de esa visibilidad, pues «tampoco los medios nos ayudan (...). Solo se ven cosas malas. La gente todavía tiene esa imagen $»^{12}$.

Precisamente, una cuestión que mediaría la visibilidad social de las mujeres musulmanas es el comportamiento social de las inmigrantes que pertenecen a esta comunidad religiosa. Al emigrar por reagrupación familiar y no contar con permiso de trabajo, se limita su espacio de vida social, que se reduce a su casa y sus amigas, creando ciertas «situaciones cerradas». Ciertamente, visibilidad social y dinámicas de socialidad están, de manera general, estrechamente

\footnotetext{
Argelina, musulmana, Zaragoza.

Marroquí, musulmana, Zaragoza.

Ídem.

Marroquí, musulmana, Zaragoza.
} 
interrelacionadas, pero en este caso esa articulación resulta particularmente significativa.

Pero, más que un comportamiento ligado a la religiosidad, esta actitud se entiende en términos culturales. Aunque la mayoría son practicantes, tal reducción del círculo de socialidad se manifiesta tanto en las «mujeres con pañuelo que sin pañuelo, practicantes que no practicantes» ${ }^{13}$. Ello estaría asociado a una tendencia a ser "vergonzosas, no es fácil que hagan relaciones con la gente», así como a cierto temor, pues «cuando no hablas y no conoces y alguien que te habla no sabes lo que te dice, se retraen porque tienen miedos» ${ }^{14}$. Se confirma que es una actitud considerada más cultural que religiosa, pues se opina que es menor en las mujeres inmigrantes musulmanas con mayores estudios, que son "como más abiertas».

Al ser inmigrantes la mayoría de las mujeres de este colectivo y al limitarse generalmente su vida cotidiana al espacio de la casa, su visibilidad social se reduce. Asimismo, en cierta forma, también coadyuva a que se mantenga la representación social dominante referida, pues estas mujeres no se articularían en dinámicas de socialidad visibilizadoras de sí mismas, que contribuyan a la reconfiguración de aquella. La mayor integración no solo estaría asociada a un mayor nivel educativo sino también a un tiempo más prolongado de inmigración. Sin embargo, la feminización de la inmigración, como hemos visto, es un fenómeno relativamente reciente, lo cual incide en esta variable temporal.

En otras comunidades religiosas minoritarias, la dimensión de la visibilidad se presenta menos marcada, dada la inexistencia de una marca visual de identidad, como el pañuelo. Así, una mujer evangélica u ortodoxa, puede pasar «socialmente» inadvertida, en un sentido visual. Sin embargo, esta ausencia no supone la inexistencia en las mujeres de una comprensión de su visibilidad social singularmente mediada por su pertenencia a una comunidad religiosa minoritaria. Por ejemplo, una mujer evangélica manifestaba, que en un principio, «nos consideraban como una secta. Entonces nosotros aceptábamos en parte esto por su desconocimiento» ${ }^{15}$.

Esta imagen de «secta» que tienen las mujeres acerca de la visibilidad social inicial de su comunidad religiosa, en el caso de ciertas

13 Española, musulmana conversa, Huesca.

14 Española, musulmana conversa, Zaragoza.

15 Argentina, evangélica, Teruel. 
denominaciones evangélicas (Iglesia Cristiana Universal), se habría visto modificada, precisamente, a partir de la creciente socialidad de sus miembros. En la medida en que "[los demás] van entrando y van conociéndonos, sobretodo a nosotros como personas, como individuos. Se dan cuenta de que amamos a Jesús y creemos en la Biblia y practicamos lo que dice en ella ${ }^{16}$. Es decir, el cambio de la representación social de la comunidad religiosa minoritaria, y en particular de sus integrantes mujeres, se considera que viene, inherentemente, de la mano de la socialidad individual de sus miembros.

Incluso se llega a aprovechar que no exista una marca visual de identidad —como el velo musulmán-, para intentar pasar socialmente inadvertidas. Una estrategia es «ser lo más normales del mundo, para que vean que el cristianismo no es un guetto, no es algo aislado del mundo. (...) trato de no estar hablando, evangelizando continuamente, sino de que lo vean con los hechos ${ }^{17}$. Estaríamos ante una suerte de estrategia de invisibilidad que deviene preferencia por una visibilidad de las acciones frente a una visibilidad de las palabras.

El resultado es significativo, pues no se trata de renunciar a su religión, sino de administrar su visibilidad desde la condición religiosa. Esto conduce a una cierta contradicción: por un lado se subraya que la comunidad religiosa no es un "guetto», y por otro se llega a proponer, como parte de esta estrategia, una cierta automarginación, un «mantenernos al margen, guardar distancias» respecto a los no miembros de la comunidad religiosa.

La solución de continuidad para evitar esa contradicción pasa por la ya anticipada visibilidad de las acciones y, en especial, de una acción que (de)muestre — esto es, que visibilice — los valores de los miembros de la comunidad religiosa. En ello coinciden tanto las féminas evangélicas como las ortodoxas. El cristianismo, según una mujer evangélica, «tenemos que sacarlo fuera (...) en la vida cotidiana. (...) no lo puedes encajonar», en unas acciones que muestren «la fidelidad, la honradez, esa responsabilidad que cada cristiano tiene y asume»; mientras que para una mujer ortodoxa, la religión implica «que la gente vea en mí un ejemplo, porque una persona cristiana debemos ser un ejemplo para la gente de alrededor, pienso yo ${ }^{18}$.

16 Ídem.

17 Dominicana, evangélica, Zaragoza.

18 Venezolana, evangélica, Zaragoza. 
Sin embargo, a pesar de que, por ejemplo, la comunidad evangélica inmigrante procede en mayor medida de países latinoamericanos, también en este caso la foraneidad se mantiene como una dimensión con un peso significativo en la comprensión de su visibilidad. Aún cuando, en esta denominación, las mujeres reconocen ese tránsito desde una representación social que las asocia a una secta hacia lo que pudiéramos denominar una visibilidad social de creciente aceptabilidad, la diferencia entre los conversos autóctonos y los miembros inmigrantes se considera muy significativa a los efectos de ese cambio en la representación social dominante. Por ejemplo, prefieren que ciertas actividades de acción social — con una importante dimensión de visibilidad - las realicen conversos, pues de lo contrario "siempre seremos las "religiones de extranjeros" ${ }^{19}$.

Se insiste en evitar una representación social de estas comunidades que suponga una doble condición de otredad: religiosa y de nacionalidad. Las mujeres serían especialmente sensibles a esta cuestión pues en su caso ello supondría una triple otredad, al agregarse la femineidad. El eje autoctoneidad-foraneidad se presenta así como dimensión crítica para la visibilidad de estas comunidades religiosas minoritarias y, en especial, para sus mujeres.

Finalmente, en ciertas denominaciones evangélicas, para las mujeres la religión es fuente de revalorización humana y dignificación desde su condición femenina, al punto de considerar que el lugar que llega a ocupar la mujer en la institucionalidad religiosa - donde puede llegar a ser pastora- implica, «en España, romper moldes, porque el machismo [aquí] está muy arraigado» ${ }^{20}$. La pertenencia religiosa se presenta, en este caso específico, no como un obstáculo para la igualdad de género, sino por el contrario favorecedora de la misma, más allá incluso de lo logrado en la propia sociedad y, por consiguiente, se entiende como un recurso de visibilidad de género positiva, al permitir el empoderamiento de la mujer. Consecuentemente, en las mujeres pertenecientes a esta comunidad religiosa hay una representación social crítica de la posición de la mujer tanto en la sociedad en general, como específicamente en otras religiones minoritarias, incluso en otras denominaciones evangélicas, a las cuales se califica como «muy cerradas, muy tradicionales».

19 Argentina, evangélica, Teruel.

20 Colombiana, evangélica, Zaragoza. 


\section{MEDIACIÓN DE LA PERTENENCIA RELIGIOSA EN LAS DINÁMICAS DE SOCIALIDAD}

Ya hemos visto que, efectivamente, visibilidad y socialidad se encuentran inheremente articuladas, distinguibles muchas veces solo desde un punto de vista metodológico. Sin embargo, resulta pertinente una indagación específica en torno a las formas a través de las cuales la membresía religiosa, a la vez que mediación de su visibilidad social, también atraviesa los vínculos y relaciones sociales en que se insertan las mujeres miembros de estas comunidades minoritarias. Esta condición de espacio público para la socialidad se expresa, sobre todo, en la conformación de la comunidad religiosa como un lugar de solidaridad.

La modernización ha empobrecido la socialidad primaria al fomentar la individualización, de manera que las comunidades religiosas se convierten en verdaderos nichos de socialidades (que sin duda también se ven afectadas al crecer) y son ineludible fuente generadora de capital social. En sintonía con esta racionalidad moderna dominante, desde las teorías sociales clásicas, la relación entre lo individual y lo social se ha presentado en tanto que tensión dicotómica. Las posturas teóricas extremas han transitado, recurrentemente, entre visiones que consideran al individuo como elemento fundamental y primario — como es el caso de la concepción del liberalismo smithiano o la acción social weberiana-, y perspectivas centradas en lo social — desde los contractualistas hasta la objetualización durkheimiana de lo colectivo y la cosificación parsoniana del sistema.

La recuperación teórica de una socialidad que proponga una articulación compleja y dinámica entre lo individual y lo colectivo, ha venido de la mano de ciertos enfoques sociológicos contemporáneos. Estas perspectivas se han fundamentado en una recuperación de la dualidad objetivo-subjetiva de lo social (Berger y Luckmann, 2001); del sentido de lo comunitario desde una ontología del «ser-encomún» de manera que el «ser mismo» es definido como «relación», «no-absolutez» o, en una palabra, comunidad (Nancy, 2001); de lo emocional como energía social fundamental (Collins, 2009); de una racionalidad comunicativa (Habermas, 1987, 1987a) que, por oposición a la racionalidad instrumental, tiene su sustento en el consenso; o de la socialidad frente a la sociedad (Maffesoli, 1993: 15), en un movimiento que apunta a «lo instituyente y lo clandestino» propio 
de la primera, en un rescate de aquellos elementos dejados de lado o considerados secundarios por la sociología oficial: «lo emocional, lo afectivo, la dimensión festiva, lúdica» (Maffesoli en Gómez, 1994: 252).

Considerando el carácter polémico de esta cuestión teórica, la presente indagación se presenta como un tema particularmente pertinente porque estas mujeres se encuentran en una situación de ruptura respecto a sus dinámicas previas de socialidad, en unos casos como resultado de la migración y en otros, de la conversión.

La comunidad religiosa deviene una suerte de asidero de sociali$d a d$, en un entorno extraño y ajeno, con un doble sentido claramente socioafectivo-funcional. Para muchas inmigrantes, la iglesia es el espacio donde "podemos acudir, (...) hay reuniones, (...) se puede hablar un poco» y en el cual, además, se encuentra ayuda más allá de instituciones como el ayuntamiento o Cáritas, tal como cita la informante; un lugar de socialidad — de reunión-, pero también oferente de respuestas a necesidades básicas (como trabajo o vivienda).

La religión se considera, en todas las comunidades religiosas minoritarias analizadas, un facilitador de integración social y laboral, que, en el caso de las mujeres se muestra paralelo a otro; a saber, las políticas sociales que despliegan las administraciónes públicas.

Ya sea el papel de dichos factores de sustitución o de complementariedad, emergen matices diferenciales en el uso de la socialidad funcional que las mujeres hacen de la religión, sea la propia o no. En este sentido, detectamos - ante la ausencia, la dificultad de acceso o siemplemente por pura instrumentalidad- un frecuente uso de socialidad funcional de los espacios de la iglesia católica (especialmente entre la comunidad ortodoxa): «la iglesia católica "ayuda mucho a la gente, le dice: 'Nosotros te ayudamos'; hablan entre ellos y te apoyan. Te dicen los cursos de español que puedes hacer, porque cuando llegas no sabes que te dicen y que hacer, pero por señales te hacen entender. Y las mujeres que me han preparado a mí los papeles son mujeres de la iglesia, que son muy buenas (...) me ayudó con el trabajo. (...) me ayudaron a encontrar casa $»^{21}$.

Es cierto que en el caso de las mujeres musulmanas inmigrantes encontramos una resistencia a participar en esos espacios de socialidad y funcionales - por ejemplo, cursos de idioma- que preparan las propias comunidades religiosas y que a menudo van dirigidos

21 Rumana, ortodoxa, Teruel. 
especialmente a las mujeres. Sin embargo, esta resistencia no se considera asociada a la dimensión religiosa, sino a las particularidades de algunas mujeres, así como también de ciertos esposos, que impiden esa socialidad.

Las propias entrevistadas de esta comunidad religiosa reconocen que «en nuestra cultura, hay algunas mujeres que son muy cerradas, muy extremistas. No se relacionan con personas de otra cultura ${ }^{22}$; y admiten que ese comportamiento puede estar dado tanto por una opción personal en algunos casos, como por la imposición de sus esposos, en otros. "Hay algunas que ni siquiera salen, ni se relacionan con los vecinos. Se quedan mudas, ciegas, no saben a dónde ir; no conocen cómo es el sistema de vida aquí (sanitario, extranjería, educación). (...) Algunos hombres creen que si la mujer sale, pues va a terminar vistiéndose como las mujeres de aquí. En otros casos, las propias mujeres tienen el miedo de salir y se dicen que por qué lo necesitan, si está mi marido conmigo ${ }^{23}$.

Se confirma así la tendencia a una menor inserción en espacios de socialidad que estudios precedentes han diagnosticado en las féminas de esta comunidad. Al ser las mujeres árabes el colectivo más aislado, su integración se está advirtiendo más compleja. Los esfuerzos por conseguir que estas puedan vivir de manera autónoma en Aragón, es un problema que han intentado abordar tanto los responsables de las comunidades islámicas en Aragón como la administración pública a través de la figura de la mediadora intercultural.

Sin embargo, el aislamiento de las mujeres musulmanas, además de no ser considerado como una tendencia mayoritaria por las entrevistadas de esta comunidad, es asociado no a los principios de la religión islámica, sino precisamente a su desconocimiento o mala interpretación. A su juicio, por una parte, «la integración se confunde con la asimilación» y por otra, existe en estos casos un desconocimiento de los derechos que el Corán reconoce para las mujeres, pues cuando "no se conocen bien los derechos de la mujer, sobre todo ella, pues ahí entra más la tradición, la cultura, vamos. Sobre todo los musulmanes practicantes, que conocemos la religión, pues estamos muy bien $»^{24}$.

\footnotetext{
22 Marroquí, musulmana, Zaragoza.

23 Española, musulmana conversa, Zaragoza.

24 Ídem.
} 
La comunidad étnico-religiosa ofrece una serie de espacios específicamente a las mujeres, como los cursos de idioma -español o árabe-, u otros más puntuales de carácter ocupacional —como costura, informática-, no solo con el objetivo de la formación, sino sobre todo para crear espacios de socialidad, principalmente en el caso de aquellas que llevan menos tiempo. «Las que llevan más tiempo ya están más integradas, muchas de ellas ya tienen amistad con la vecina porque en sus países es así» ${ }^{25}$. Tales espacios, sin embargo, no limitan el acceso por la dimensión religiosa, sino que «está abierto a todas las mujeres. Incluso si vinieran mujeres que no son musulmanas también las aceptaríamos» ${ }^{26}$. Es decir, incluso el aspecto más funcional del espacio aparece en cierta medida subordinado al encargo socializante, precisamente como respuesta a la circunstancia, antes descrita, de cierto aislamiento característico de las mujeres pertenecientes a esta minoría religiosa.

Pero la dimensión socioafectiva de la mediación de la religiosidad en las dinámicas de socialidad se presenta, de manera general, como un aspecto de especial importancia para estas mujeres en las denominaciones religiosas minoritarias. La comunidad religiosa es un espacio de socialidad con una especial dimensión afectivoemocional que, siguiendo a Collins (2009), convierte esa pertenencia religiosa en fuente de energía. "Yo me apoyo mucho en esta [en la comunidad] porque cuando vienes, dices: ¿dónde voy?, no sé hablar bien; entonces rezando te ayuda ${ }^{27}$. Se recuerda que, ante determinadas circunstancias difíciles, la comunidad religiosa ha sido fuente de sostén emocional: «mi hijo tuvo un accidente muy grave y me emocionó mucho. (...) acudieron al hospital gente que no la he visto en mi vida, gente de la iglesia que yo no conocía para nada, pero vinieron para no sentirme sola y para apoyarme y a mí me emocionó mucho. Es toda la comunidad y es que te apoyan y para mí fue muy importante ${ }^{28}$.

En el caso de las musulmanas inmigrantes, incluso se reconoce una tendencia al reforzamiento de la fe y de la implicación en la vida religiosa, a ser más practicantes, precisamente como recurso de socialidad que aporta un asidero emocional. Este reforzamiento

\footnotetext{
25 Ídem.

26 Siria, musulmana, Zaragoza.

27 Marroquí, musulmana, Zaragoza.

28 Ecuador, evangélica, Zaragoza.
} 
de la práctica religiosa, en las mujeres musulmanas inmigrantes, es resultado de una necesidad frente a la nueva sociedad y el desconocimiento en ella de su religión, así como también de la propia inserción de dinámicas de asociacionismo. «Al llegar aquí, tengo la sensación de que tengo que saber más sobre mi religión, porque antes no necesitaba saberlo, practicarlo. (...) después de entrar en el ámbito del asociacionismo, me empezaron a preguntar, sobre todo del velo, que para las mujeres es algo muy anormal. Entonces empecé a buscar y a saber más cosas sobre mi religión ${ }^{29}$. Esto, junto a la interacción con otras religiones, conduce a un mayor convencimiento religioso y a considerar que, como mujer, «para mí la religión más adecuada es el Islam».

Al mismo tiempo, la visualidad explícita característica de la condición de mujer musulmana —el uso del velo o pañuelo-, implicaría también una circunstancia que, en cierta medida, provoca una mayor posibilidad de socialidad. Se apunta que «la religión sí me ayuda a llegar a la gente. Lo exótico de mi religión hace que sea un tema habitual de la gente», aunque — en ocasiones- esa curiosidad se expresa en «miradas que molestan. Ojalá vinieran y me preguntaran. A mí me gusta que vengan y me pregunten, en buena forma. Pero esas miradas sí molestan $»^{30}$. La marca visible del pañuelo, de esta forma, puede ser un recurso facilitador de socialidad o de rechazo, según la actitud que asuma el otro no musulmán.

El reforzamiento de la religiosidad, en el caso de las mujeres musulmanas, no solo está relacionado con el saber para explicar, sino también con el sentir, con lo afectivo. En sus países de origen «todo el mundo es igual, la sociedad te ayuda, aquí te sientes como desvalido. Cuando llegas lo primero que haces es te unes a los tuyos, vas a la mezquita que es nuestro centro de unión y así como que te ayuda y te da un poco de fuerza, de moral. Y es más, son más practicantes aquí que en sus países. Que yo pensaba que era al contrario porque hay más dificultad y lo más fácil sería el anonimato o sentirte un español» ${ }^{31}$.

La comunidad religiosa como espacio de socialidad, se suele asociar, en el caso de los inmigrantes — tanto hombres como mujeres- a unas condiciones de posibilidad para la superación de cierta

\footnotetext{
29 Marroquí, musulmana, Zaragoza.

30 Ídem.

31 Argelina, musulmana, Zaragoza.
} 
tendencia a buscar soluciones individuales ilegales a las situaciones de carencia que puede afrontar el emigrante, "porque hay mucha gente que viene aquí y no encuentra trabajo y se callan y hay gente que lo pasa mal pero se encierran y como no acuden a iglesia se vuelven peores o empiezan a hacer cosas malas» ${ }^{32}$. Este mejoramiento individual a través de lo grupal se halla en relación con la estrategia de visibilidad que busca reforzar una imagen de colectivo caracterizado por ciertos valores, que contribuya a la configuración de una representación social positiva de estas comunidades minoritarias religiosas.

Esta perspectiva de la comunidad religiosa como escenario de asidero positivo para la individualidad, si bien es general, tiene sus particularidades para las mujeres. Se siente que la religión, «como mujer, me ayuda en todas las áreas de la vida. (...) Como esposa, como madre y también en el trabajo». Se siente que la religiosidad resulta una mediación que facilita la contribución personal a la sociedad, pues «soy la primera escuela para mis hijos» —es decir, se destaca ese rol tradicionalmente femenino-, por eso, la religión «es mi guía, mi constitución, mi identidad, mi vida. Todo» ${ }^{33}$.

En la biblia, explica una informante evangélica, se encuentran consejos para la vida matrimonial —sobre el perdón, por ejemplo—, y la educación de los hijos se concibe desde una perspectiva, en este caso, cristiana. Al ser entendida como «una relación con Dios las 24 horas», la religión, de forma inherente, «te marca individualmente, pero también en tus relaciones, en tu manera de que los demás te vean (...) es que no lo separo. No es mi vida seglar y mi vida secular. (...) Si tengo una vida cristiana o religiosa, diría, yo personalmente, del domingo, y luego hacer lo que quiero [el resto del tiempo], eso no es cristiano» ${ }^{34}$.

Aquí se plantea una cuestión especialmente interesante en la comprensión de la mediación de la religiosidad en la socialidad. La religión es concebida como una relación personal con Dios, pero que, al mismo tiempo, se realiza con los demás, esto es, en comunidad, en la iglesia. Lo que pudiera parecer una contradicción, se considera totalmente coherente, porque "yo no puedo decir "Amo a Dios" y aborrecer a mi hermano, no es compatible. Decir que amo

32 Rumana, ortodoxa, Teruel.

33 Venezolana, evangélica, Zaragoza.

34 Argentina, evangélica, Teruel. 
a dios y quedarme paralizada ante las necesidades que hay; al menos tengo que orar por él» ${ }^{35}$.

El hecho de que ese encuentro personal con Dios tenga como espacio principal un escenario de carácter colectivo, tiene una explicación que esencialmente transita, retomando nuevamente a Collins (2009), por la dimensión emocional. La alabanza «es muy especial, te contagias, te salen lágrimas... Nos saludamos, hay libertad para hablar, para expresarse todos: niños, adultos... Hay armonía, hay perdón... Disfrutamos como iglesia. Es una bendición». En la propia biblia, se recuerda, se conmina al encuentro colectivo como camino para la manifestación divina. Por eso, «donde estemos más, hay más pasión. (...) La iglesia es muy importante, los primeros discípulos se reunían. El amor de dios te atrae. Si un cristiano se aparta, pues se apaga. La iglesia es como la llama, donde tú recibes, pero también das» ${ }^{36}$.

Pero además de ser un espacio de encuentro colectivo general, en las distintas comunidades religiosas comunitarias, la mujer tiene sus propios espacios de socialidad. En relación con este aspecto, es significativa la lectura que se hace de tales espacios por parte de las mujeres de diferentes denominaciones, en especial la evangélica y la musulmana. En esta última, los principios de la propia comunidad religiosa establecen una separación entre hombres y mujeres en la mezquita, mientras en la primera la creación de tales espacios específicamente femeninos es resultado de una decisión de las propias mujeres. Sin embargo, en ambos casos, hay lecturas que asocian estos escenarios femeninos a la autorrealización, aun cuando en un caso sean establecidos o impuestos y en el otro creados a propuesta de las propias mujeres.

Las musulmanas hacen una lectura positiva de la separación espacial - y, por ende, de socialidad — entre hombres y mujeres en la mezquita, al punto de que la segmentación deviene condición misma de la posibilidad de unos espacios de socialidad solamente femeninos. Hay así una oposición entre la visibilidad social negativa que se tiene de esta circunstancia (vista como discriminatoria) y la lectura positiva de socialidad que hacen las mujeres de la misma. Se entiende como la posibilidad de crear «como una microsociedad femenina en la que se está a gusto. Es una forma diferente de ver la

35 Colombiana, evangélica, Zaragoza.

36 Argentina, evangélica, Teruel. 
sociedad. (...) [En ese espacio de mujeres] nos expresamos mejor. Nosotras nos sentimos más cómodas... Si hay un hombre extraño pues no te vas a poner a contar chistes, ni vas a estar cómoda (...), sin embargo con la sociedad de mujeres puedes ponerte a cantar, a bailar. (...) es una sociedad, una microsociedad». ${ }^{37}$

De hecho, se considera que, como «la mayoría de las mujeres son vergonzosas, que les da vergüenza que alguien les mire, pues entonces esta situación tan cercana... [si en la mezquita estuvieran junto con los hombres] se quedarían en su casa, la mayoría no iría ${ }^{38}$. Esta separación es positiva, también, en un sentido funcional, ya que permite por ejemplo poder controlar a los niños, que se quedan en el lugar reservado a las mujeres, en lugar de «estar deambulando por toda la mezquita». Lo que explica esa lectura no discriminatoria de la separación espacial es un concepto diferente de igualdad, que «no es igual a lo que el mundo europeo o occidental entiende por igualdad. Nosotros entendemos por igualdad, igualdad de conocimiento, igualdad de a una buena acción una buena recompensa y a una mala acción una mala recompensa. Pero no en los papeles de la vida» ${ }^{39}$.

En la comunidad evangélica, por el contrario, la existencia de espacios de socialidad solamente femeninos es resultado de una propuesta de las propias mujeres. Se trata de espacios no asociados al lugar de culto, sino de socialidad más allá de este sitio, aunque no necesariamente al margen de él. Así, por ejemplo, en el caso de la comunidad analizada, las mujeres se reúnen una vez al mes (tercer domingo), porque «era nuestro deseo. No solo para hablar de la biblia y oración, sino de todo, conocernos más. (...) El domingo la mayoría descansa. Pues ahí nos reunimos para comer, compartimos la comida — nunca nos falta, siempre sobra-, invitamos. Porque la amistad se hace comiendo. Es una familia. Y después conversamos nuestras cosas. Cada una tiene su participación. Vamos haciendo sugerencias. De ahí, por ejemplo, han salido hermanas que tienen capacidad de arte, (...) a dirigir grupos de teatro ${ }^{40}$.

Lo significativo es que, sea precisamente en la comunidad religiosa minoritaria en la cual la mujer tendría la mayor participación y empoderamiento —incluso puede ser pastora-, donde existe esa

37 Marroquí, musulmana, Zaragoza.

38 Española, musulmana conversa, Zaragoza.

39 Siria, musulmana, Zaragoza.

40 Argentina, evangélica, Teruel. 
necesidad de crear, a partir de la pertenencia religiosa, espacios de socialidad femeninos distintos al momento de culto. Incluso, las propias mujeres han conminado a que los hombres creen espacios similares, de socialidad, "los animamos, los motivamos a que tengan su tiempo como varones. Nosotras creo que lo necesitamos más, o quizás estamos más motivadas, no con la iglesia, sino porque nos gusta más estar juntas, compartir. A los hombres les cuesta reunirse solos».

Se trataría, en cierta medida, de una socialidad femenina que no tiene un sentido de reivindicación, pues es la comunidad minoritaria en que las mujeres se sienten más valoradas, empoderadas, y en la cual tienen, efectivamente, acceso a posiciones de poder dentro de la institucionalidad religiosa. Aquí la religión sería mediación a partir de la cual se gestarían nuevos espacios de socialidad femenina más allá de la religiosidad misma, que si bien no llegan a cobrar autonomía respecto a aquella - puesto que tienen su fundamento en ella, y en cierta forma son una continuidad del espacio de culto, de la alabanza—, apuntan a una socialidad o comunidad en sí misma, más allá del fin religioso.

Sin embargo, de manera contradictoria, si bien las mujeres de esta comunidad religiosa son las tienen más posibilidades de participación real, confiesan que, de haberse encontrado con una comunidad religiosa más tradicional, que no diera «ese valor a la mujer, pues yo lo aceptaría, y lo respetaría. Me sujetaría, porque una de las cosas que el ser humano tiene que hacer es sujetarse y respetar a las autoridades que Dios ha puesto en la iglesia... No puede ser que porque no me gusta, pues me voy. (...) El pastor tiene que responder a la iglesia, como la iglesia al pastor. Esa sujeción es muy importante, pero no por imposición, sino por amor. Estar en una congregación es aceptarla» ${ }^{41}$. Es decir que, incluso en aquellas comunidades donde la mujer puede llegar a crear sus propios espacios de socialidad, la mediación religiosa sería siempre, en última instancia, respetada y aceptada, aún cuando supusiese unos principios diferentes en relación con la condición de la mujer como tal.

41 Colombiana, evangélica, Zaragoza. 


\section{CONCLUSIONES O CÓMO LA RELIGIOSIDAD MEDIA EN LA VISIBILIDAD Y SOCIALIDAD DE LA MUJER}

La religiosidad es una dimensión que media, en todas las comunidades religiosas minoritarias, la visibilidad y la socialidad de la mujer. A la singularidad de la pertenencia religiosa se agrega la especificidad que supone la condición femenina, con los principios, normas y particularidades que se derivan de ello en su entrecruzamiento con la religión, así como la muy frecuente condición foránea de las integrantes de estas mujeres religiosas.

Si bien existen diferencias entre las distintas denominaciones religiosas - de forma coherente con sus especificidades y la diversidad religiosa- hay en general aspectos transversales. En primer lugar, la especial dimensión afectiva que se otorga a la comunidad religiosa como recurso de socialidad, sobre todo por el estado de desanclaje que se deriva de la condición de inmigrante. Pero, al mismo tiempo, la religión también tiene un marcado sentido funcional en las dinámicas de inserción social de las mujeres, al ayudarlas en aspectos como el laboral o la vivienda. Lo funcional y lo emocional se articulan en la socialidad que supone la pertenencia religiosa.

Existe, en general, una percepción de una visibilidad social de foraneidad de estas comunidades y sus mujeres. Ciertamente, la mayoría de los miembros de estas denominaciones son inmigrantes, pero lo significativo es que, incluso en el caso de las conversas, se reconoce una cierta imagen de extranjerización de las mismas, plasmado en el discurso de «traición» a la nación. Frente a esa imagen de una visibilidad social marcada por la foraneidad y la otredad religiosa, se ponen en práctica estrategias para tanto reducir esta última - sobre todo en el caso de aquellas denominaciones donde no existen marcas visuales de pertenencia-, como para minimizar la primera - a través de una acción social intencionadamente más marcada de los miembros españoles.

Estamos frente a una doble estrategia para la «desextranjerización» de la condición religiosa, que pasa por dos actuaciones complementarias, pero que pudieran entenderse como antagónicas: por una parte cierta reducción de la visibilidad (de los miembros extranjeros) que tiene lugar en la dimensión simbólica y, por otra, un reforzamiento de la acción social efectiva (de los miembros nacionales). Resulta especialmente relevante el juego de los sentidos de pertenencia que permite articular una estrategia que pretende 
eliminar la condición religiosa como marca social identitaria, sin que ello se considere una actuación reprobable. Probablemente, la flexibilidad (o, en términos baumanianos, el carácter líquido) de lo emocional - central, como hemos visto, en la lectura que se hace de la religiosidad-permite este comportamiento. En última instancia, lo funcional de lograr una integración social «normal» se impone, y se trata de reducir la única dimensión de otredad (la religiosa) que es posible, dado que la foraneidad es mucho menos reductible.

Visibilidad y socialidad se presentan, efectivamente, en una mediación mutua. Ello se pone de manifiesto en la correspondencia entre ciertas circunstancias o estrategias de visibilidad, y determinadas dinámicas de socialidad. Así, en el caso en que existe una determinada marca de visualidad pública (velo), esta se asume como dimensión que atraviesa la socialidad de las mujeres, en un sentido que puede ir desde actitudes de encerramiento hasta el hecho de aceptar que esta marca de visualidad pudiera ser una motivación para una aproximación de los otros a partir de la indagación respetuosa sobre su sentido. Mientras tanto, en el caso de aquellas comunidades religiosas minoritarias en las cuales no existen signos visuales explícitos de pertenencia, se pondría de manifiesto una estrategia de invisibilidad social - la normalización de su presencia paradójicamente se traduce en pasar desapercibidos-, precisamente para evitar una distinción social, que vendría a reforzar la que supone el hecho de que la mayoría de sus miembros sean inmigrantes.

Si bien resulta general una comprensión de la visibilidad como marcada por la otredad, hay gradaciones o tipologías distintas de visibilidad. Así, hay comunidades que, se asume, tienen una visibilidad social más negativa, tanto de manera general como en particular de las mujeres que la integran; es el caso de las mujeres musulmanas. Tal imagen está presente incluso entre las mujeres pertenecientes a otras denominaciones, lo cual muestra que las diversidades religiosas atraviesan las lecturas recíprocas de las propias informantes, más allá de compartir múltiples circunstancias de otredad: religión, género, nacionalidad. También resulta significativo el papel que, en tal sentido, se otorga a los medios de comunicación en la construcción de esa representación social hegemónica de contenido negativo. De igual forma, es relevante que esa visibilidad se asocie a cierto comportamiento de socialidad de muchas de las mujeres de esta denominación, aunque tal actitud se considera más cultural que religiosa. Es decir, la construcción social de esa visibilidad. En 
ese proceso de configuración de la visibilidad social $-\mathrm{y}$ de la propia percepción individual sobre la misma- se articulan, por supuesto, tanto las representaciones sociales hegemónicas, como las representaciones individuales de los propios sujetos, así como sus actuaciones en el entorno de las relaciones y redes sociales.

En conclusión, en última instancia, la articulación de visibilidad y socialidad tienen como eje transversal la otredad múltiple y compleja que se deriva de la pertenencia a estas comunidades religiosas minoritarias: la otredad femenina, la otredad de la foraneidad (incluso en las conversas) y la otredad religiosa.

\section{BIBLIOGRAFÍA}

Anderson, B. (1993): Comunidades imaginadas. Reflexiones sobre el origen y la difusión del nacionalismo. México, Fondo de Cultura Económica.

Bates, Ü.; Denmark, F.; Held, V.; Helly, D.; Hune, S.; Lees, S.; Pomeroy, S.; Somerville, C.; Rosenberg, S. (1994): Women's realities, women's choices: An Introduction to Women Studies. New York, Oxford University Press.

Berger, P. y Luckmann, T. (2001): La construcción social de la realidad. Buenos Aires, Amorrortu.

Collins, R. (2009): Cadenas de rituales de interacción. Barcelona, Anthropos.

Dietz, G. (2004): «Mujeres musulmanas en Granada: discursos sobre comunidad, exclusión de género y discriminación etnorreligiosa». Migraciones Internacionales, 2 (3), enero-junio de 2004, pp. 5-33.

Gómez, L. E. (1994): «Vida intelectual y conocimiento. Un diálogo con Michel Maffesoli». Sociológica, 26 (9), septiembre-diciembre de 1994, pp. 245-253.

Habermas, J. (1987): Teoría de la acción comunicativa. I. Racionalidad de la acción y racionalización social. Madrid, Taurus.

- (1987a): Teoría de la acción comunicativa. II. Crítica de la razón funcionalista. Madrid, Taurus.

Hernando de Larramendi, M. y García Ortiz, P. (dirs.) (2009): religion.es Minorías religiosas en Castilla-La Mancha. Barcelona, Icaria.

Jodelet, D. (1986): «La representación social: fenómenos, concepto y teoría», en Moscovici, S. (comp.): Psicología Social II. Pensamiento y vida social. Psicología social y problemas sociales. Barcelona, Ediciones Paidós.

Maffesoli, M. (1993): El conocimiento ordinario. México, Fondo de Cultura Económica.

Moscovici, S. y Hewstone, M. (1986): «De la ciencia al sentido común», en Moscovici, S. (comp.): Psicología Social II. Pensamiento y vida social. Psicología social y problemas sociales. Barcelona, Ediciones Paidós. 
Nancy, J. (2001): La comunidad desobrada. Madrid, Arena Libros.

PACE, E. (1995): «Tendencias y corrientes de la Sociología de las Religiones». Sociedad y Religión, 13, pp. 101-119.

RADAY, F. (2004): «Culture, religion and gender». I.CON, 1 (4), pp. 663-715.

Rodríguez Martínez, P. (2005): «Identificaciones de sexo-género de mujeres migrantes marroquíes y británicas en Almería». Revista Española de Investigaciones Sociológicas (REIS), 110/05, pp. 137-148.

Rozenberg, D. (1996): “Minorías religiosas y construcción democrática en España. (Del monopolio de la Iglesia a la gestión del pluralismo)». Revista Española de Investigaciones Sociológicas (REIS), 74, Abril-Junio, 1996, pp. 245-265.

Sanz Hernández, A. (2009): «Mujer y religión», en Gómez Bahillo et al.: Construyendo redes. Minorías religiosas en Aragón. Barcelona: Icaria Editorial, pp. 71-117.

Sotolongo Codina, P. L. y Delgado Díaz, C. J. (2006): «La intersubjetividad social, las estructuras sociales objetivadas y las subjetividades sociales individuales», en Sotolongo Codina, P. L. y Delgado Díaz, C. J. (comps): La revolución contemporánea del saber y la complejidad social. Hacia unas ciencias sociales de nuevo tipo. Buenos Aires: Consejo Latinoamericano de Ciencias Sociales, pp. 131-164.

TARDUCCI, M. (1992): «Los estudios sobre la Mujer y la Religión: Una introducción». Sociedad y Religión, 9, pp. 105-112.

TARré Chamorro, S. (2008): «Las conversiones femeninas al Islam en España (1995-2006)», en Téllez Infantes, A. y Eloy Martínez Guirao, J. (Coords.): Investigaciones antropológicas sobre género: de miradas y enfoques. España, Seminario Interdisciplinar de Estudios de Género del Vicerrectorado de Estudiantes y Extensión Universitaria de la Universidad Miguel Hernández, pp. 97-123. 